\title{
Evaluation of Nickel-Yttria Stabilized Zirconia Anode Degradation during Discharge Operation and Redox Cycles Operation by Electrochemical Calculation
}

Takaaki Shimura $^{1}$, Zhenjun Jiao ${ }^{1,2}$, and Naoki Shikazono ${ }^{1,2}$

${ }^{1}$ Institute of Industrial Science, The University of Tokyo, 4-6-1, Komaba, Meguro-ku, Tokyo 153-8505, Japan

${ }^{2}$ CREST, JST

Gobancho 7, Chiyoda-ku, Tokyo 102-0076, Japan

Takaaki Shimura (corresponding author) : tshimura@iis.u-tokyo.ac.jp

Tel \& fax : +81354526777

\section{Abstract}

Degradation of Solid Oxide Fuel Cell (SOFC) anode during discharge operation and redox cycles operation were evaluated by three-dimensional electrochemical calculations using a Lattice Boltzmann method (LBM). Three dimensional microstructures were obtained by Focused Ion Beam Scanning Electron Microscopy (FIB-SEM) reconstruction. In the electrochemical calculations, changes in exchange current density and ionic conductivity of Yttria stabilized Zirconia (YSZ) during the operations were assumed and their values were calculated by fitting the calculated overpotential values to the experimental ones. Changes in triple phase boundary density calculated from the 
reconstructed microstructures were inconsistent with the gradual degradation observed during repeated redox-discharge cycles. Changes of the fitted exchange current density and YSZ ionic conductivity values in both discharge operation and redox cycle operation showed same tendency as the experimental results. Change in exchange current density or YSZ ionic conductivity should be considered as an essential factor which governs the cell performance change regardless of the redox treatment.

Keywords: solid oxide fuel cells, redox, 3D reconstruction, focused ion beam - scanning electron microscopy, lattice-Boltzmann method

\section{Introduction}

Tolerance against redox cycles is one of the most important issues to achieve stable operation of solid oxide fuel cells (SOFCs). In cases of system shutdown for maintenance or by accidental power loss etc., undesirable increase of oxygen partial pressure in the anode side will take place. Nickel, which is the most common electron conductor in the anode, will be oxidized and this results in volume expansion of the anode. When the oxygen partial pressure in the anode side decreases again, nickel is reduced accompanied by the volume shrinkage. Due to the large volume expansion from $\mathrm{Ni}$ to $\mathrm{NiO}$ (about $70 \%$ $[1,2]$ ) and volume shrinkage from $\mathrm{NiO}$ to $\mathrm{Ni}$ (about $42 \%$ [2]), irreversible microstructure changes after the redox cycles lead to degradation of the cell performance $[1-5]$. 
Recently, quantitative analysis of anode microstructure using dual beam focused ion beam and scanning electron microscopy (FIB-SEM) has been conducted [6-8]. In our previous work, FIB-SEM was applied to evaluate the microstructure change during redox cycles, and the relationship between the microstructure parameters and the cell performance was investigated [9]. Redox followed by $20 \mathrm{~h}$ discharge was repeated using YSZ electrolyte-supported cell with Ni-YSZ anode. Performance degradation was observed during the discharge process. From impedance measurement, both ohmic and polarization resistances increased during the discharge process. On the other hand, decrease in polarization resistance was observed just after every redox treatment, whereas ohmic resistance remained nearly unchanged just after the redox process. During the subsequent discharge process, both polarization and ohmic resistances increased again. Showing performance enhancement just after each redox process and degradation after subsequent discharge process, cell performance showed gradual degradation as the redoxdischarge cycles are repeated. From the microstructure analysis, active triple phase boundary (TPB) density increased just after the redox process and decreased during the discharge process. This TPB change was consistent with the polarization resistance change mentioned above. However, active TPB density showed gradual increase as the redox-discharge cycles are repeated. This is inconsistent with the gradual increase of polarization resistance during repeated redox-discharge cycles. Therefore, it becomes unclear that the degradation during discharge is solely attributed to the decrease of TPB density. It is implied that cell performance is dominated not only by the microstructure change, but also by the other factors.

As for the factors which affect the cell performance, two parameters were considered in this study. First is the local exchange current density at TPB, which represents the electrochemical reaction rate at the reaction site. There are several studies 
on the local exchange current density values at TPB using Ni-YSZ patterned electrodes. However, reported values show large variations [10-12]. In addition, it is not fully understood whether the exchange current density values from the patterned anodes can be applied to the porous ones. Furthermore, it is reported that segregation of impurities at TPB will increase the overpotential, which means that local exchange current density might deteriorate during the operation. [13-15]. Therefore, the change in exchange current density can be considered as one of the factors which leads to the change in electrode performance during the operation.

Second possible factor is the YSZ ionic conductivity deterioration [17, 18]. Several researchers reports that the existence of $\mathrm{Ni}$ accelerates the phase transition of YSZ from cubic to tetragonal phases under reduced atmosphere, which results in faster degradation of YSZ ionic conductivity $[16,19,20]$. Formation of tetragonal YSZ at Ni/YSZ grain boundaries is observed $[21,22]$. Nickel can dissolve into YSZ during the co-sintering of $\mathrm{NiO}$ and YSZ [20], which implies that the phase transition of YSZ is enhanced in the composite Ni-YSZ anode. Therefore, decrease in YSZ ionic conductivity can be another factor of cell performance deterioration.

In this study, exchange current density and YSZ ionic conductivity were considered as the degradation factors, and their changes during discharge operation and redox cycles operation were evaluated. In order to evaluate the electrode performance, three dimensional lattice-Boltzmann method (LBM) calculations were conducted [23, 24] using the anode microstructure reconstructed by FIB-SEM. Values of exchange current density and YSZ ionic conductivity were estimated by fitting the calculated overpotential values to the experimental ones. 


\section{Methods}

\subsection{Experiments}

Fabrication process of electrolyte supported cell is described in Ref. [9]. NiO$8 \mathrm{YSZ}$ composite powder was used as anode material. The ratio of $\mathrm{NiO}$ to YSZ is $60: 40$ vol. \%. Redox cycles test was conducted as described in Ref. [9]. Redox treatment was conducted between every $20 \mathrm{~h}$ discharge operation and repeated for ten times ("10 redox test"). In this study, "220 h discharge test" was additionally carried out. In the same way as the "10 redox test", current density was set at $0.2 \mathrm{~A} / \mathrm{cm}^{2}$. Humidified hydrogen $(5 \%$ $\mathrm{H}_{2} \mathrm{O}$ ) was supplied, and all tests were carried out at $800{ }^{\circ} \mathrm{C}$. Fuel utilization is calculated as $9.53 \%$ based on the applied current density. Terminal voltage and electrochemical impedance between the anode and the reference electrode were measured. The reference electrode is a platinum wire wound around the rim of the YSZ electrolyte. Collected impedance data were fitted with the equivalent circuit to calculate the ohmic and polarization resistances [9]. The electrochemical impedance measurements were conducted at open circuit voltage (OCV) after every $20 \mathrm{~h}$ discharge. Then, the microstructures were reconstructed using FIB-SEM. The operation sequences are summarized in Table1. Microstructure parameters are calculated as described in Ref. [9].

For the LBM calculations, reconstructed microstructures were all rescaled from voxel size of $30 \mathrm{~nm}$ to $120 \mathrm{~nm}$ due to the computational cost. The number of voxels used in the LBM simulations are shown in Table1. It is reported that voxel size of at least $124 \mathrm{~nm}$ is required for the overpotential calculation of the anode [23]. 
Table 1: Operation sequences for the sample

\begin{tabular}{|c|c|c|c|}
\hline Notation & Test sequences & Number of voxels & Number of voxels \\
\hline & & $\begin{array}{l}\text { for microstructure } \\
\text { analysis (Voxel size } \\
=30 \mathrm{~nm} \text { ) }\end{array}$ & $\begin{array}{l}\text { for } \mathrm{LBM} \quad \text { (Voxel } \\
\text { size }=120 \mathrm{~nm})\end{array}$ \\
\hline $\begin{array}{l}\text { "Initial reduction" } \\
{[9]}\end{array}$ & $\begin{array}{l}\text { After initial } \\
\text { reduction }\end{array}$ & $836 \times 288 \times 416$ & $208 \times 72 \times 104$ \\
\hline $\begin{array}{l}\text { "20 h discharge" } \\
{[9]}\end{array}$ & $20 \mathrm{~h}$ discharge & $728 \times 320 \times 348$ & $180 \times 80 \times 88$ \\
\hline "1 redox" [9] & $\begin{array}{l}20 \mathrm{~h} \text { discharge }+ \\
\text { redox }\end{array}$ & $724 \times 280 \times 348$ & $180 \times 68 \times 88$ \\
\hline $\begin{array}{l}\text { "1 redox and } 20 \mathrm{~h} \\
\text { discharge " [9] }\end{array}$ & $\begin{array}{l}20 \mathrm{~h} \text { discharge }+ \\
\text { redox }+20 \mathrm{~h} \\
\text { discharge }\end{array}$ & $732 \times 280 \times 424$ & $180 \times 68 \times 104$ \\
\hline $\begin{array}{l}\text { "4 redox and } 20 \mathrm{~h} \\
\text { discharge" }[9]\end{array}$ & $\begin{array}{l}20 \mathrm{~h} \text { discharge }+4 \\
\times(\text { redox and } 20 \mathrm{~h} \\
\text { discharge })\end{array}$ & $724 \times 260 \times 320$ & $184 \times 60 \times 80$ \\
\hline $\begin{array}{l}\text { "10 redox and } 20 \mathrm{~h} \\
\text { discharge" [9] }\end{array}$ & $\begin{array}{l}20 \mathrm{~h} \text { discharge }+10 \\
\times(\text { redox and } 20 \mathrm{~h} \\
\text { discharge })\end{array}$ & $740 \times 264 \times 372$ & $184 \times 64 \times 92$ \\
\hline $\begin{array}{l}\text { "100 h discharge" } \\
{[9]}\end{array}$ & $100 \mathrm{~h}$ discharge & $744 \times 228 \times 372$ & $184 \times 64 \times 92$ \\
\hline "220 h discharge" & $220 \mathrm{~h}$ discharge & $700 \times 304 \times 396$ & $172 \times 76 \times 99$ \\
\hline
\end{tabular}




\subsection{Numerical simulation}

Assuming that $\mathrm{Ni}$ and YSZ are perfect electronic or ionic conductors, the diffusion equations of gas, electron and ion are written as follows:

$$
\begin{gathered}
\nabla\left(D_{1} \nabla C_{\mathrm{H}_{2}}\right)+\nabla\left(D_{1}^{\prime} \nabla p_{\mathrm{t}}\right)=\frac{i_{\text {reac }}}{2 F} \\
\nabla\left(D_{2} \nabla C_{\mathrm{H}_{2} \mathrm{O}}\right)+\nabla\left(D_{2}^{\prime} \nabla p_{\mathrm{t}}\right)=-\frac{i_{\text {reac }}}{2 F} \\
\nabla\left(\frac{\sigma_{\mathrm{e}^{-}}}{F} \nabla \tilde{\mu}_{\mathrm{e}^{-}}\right)=-i_{\text {reac }} \\
\nabla\left(\frac{\sigma_{\mathrm{O}^{2-}}}{F} \nabla \tilde{\mu}_{\mathrm{O}^{2-}}\right)=i_{\text {reac }}
\end{gathered}
$$

where $C_{i}$ stands for the molar fraction of each gas species, and $p_{t}$ is the total gas pressure. $D_{\mathrm{i}}$ is a diffusion coefficient for each species, and $D_{i}^{\prime}$ is a coefficient for total gas pressure gradient.i $\tilde{\mu}_{i}$ stand for the electrochemical potentials of electron and oxygen ion. $\sigma_{i}$ stand for the conductivities of ion and electron. $F$ is the Faraday constant. $i_{\text {reac }}$ is the reaction current at local TPB defined as follows :

$$
i_{\text {reac }}=i_{0} L_{\mathrm{TPB}}\left\{\exp \left(\theta_{a} \frac{F}{R T} \eta\right)-\exp \left(-\theta_{c} \frac{F}{R T} \eta\right)\right\}
$$

where $i_{0}$ is the local exchange current density, $L_{\mathrm{TPB}}$ is local active TPB density, and $\eta$ is the local overpotential. $\theta_{a}$ and $\theta_{c}$ are the anodic charge transfer coefficient and cathodic charge transfer coefficient, respectively. Values of $\theta_{a}$ and $\theta_{a}$ are given as 2 and 1, respectively [25].

In this work, Cylindrical Pore Interpolation Model (CPIM) is used for the gas diffusion model [26]. $D_{i}$ and $D_{i}^{\prime}$ are derived from the CPIM model as follows: 


$$
\begin{gathered}
D_{i}=\left[\frac{y_{i}}{\left(D_{A}\right)_{i j}} \sqrt{\frac{M_{i}}{M_{j}}}+\frac{y_{i}}{\left(D_{A}\right)_{i j}}\right]^{-1} \\
D_{i}^{\prime}=D_{i}\left[\frac{1}{\left(D_{A}\right)_{i j} A_{A} \sqrt{M_{j}}}-\frac{1}{R T}\right]
\end{gathered}
$$

where $M_{i}$ is the mass of molecules. $\left(D_{A}\right) i j$ and $A_{A}$ are interpolated diffusion coefficient and pressure gradient coefficient, respectively [25].

$$
\begin{aligned}
\left(D_{A}\right)_{i j} & =\left[\frac{1}{D_{i j}}+\frac{1}{D_{i k}}\right]^{-1} \\
A_{A} & =\left[\frac{1}{A_{c}}+\frac{1}{A_{k}}\right]^{-1}
\end{aligned}
$$

$D i, j$ and $D i, k$ represent binary and Knudsen diffusion coefficients, respectively [23, 24]. $A_{c}$ and $A_{c}$ represent coefficients of pressure gradient as follows:

$$
\begin{gathered}
\mathrm{A}_{c}=\frac{8 \mu}{C_{t} r^{2} \sum_{i} y_{i} \sqrt{M_{i}}} \\
\mathrm{~A}_{k}=\frac{3}{4 r} \sqrt{\frac{\pi R T}{2}} \\
\mu=\sum_{i=1}^{n} \frac{y_{i} \mu_{i}^{0}}{\sum_{j=1}^{n} y_{i} \varphi_{i j}} \\
\varphi_{i j}=\frac{\left[1+\left(\mu_{i}^{0} / \mu_{j}^{0}\right)^{1 / 2}\left(M_{j} / M_{i}\right)^{1 / 4}\right]^{2}}{\left[8\left(1+M_{i} / M_{j}\right)\right]^{1 / 2}}
\end{gathered}
$$

For the exchange current density $i_{0}$, data from patterned anode experiments by Bieberle, et al. were used as the reference model [24].

$$
i_{0}=0.0013 \times p_{\mathrm{H}_{2}}^{-0.03} p_{\mathrm{H}_{2} \mathrm{O}}^{0.4} \exp \left(-\frac{0.849 \times 10^{5}}{R T}\right)
$$


For the reference values of electronic and ionic conductivities, following equations by Anselmi-Tamburini, et al. [27] and Ferguson, et al. [28] were used.

$$
\begin{array}{r}
\sigma_{\mathrm{e}^{-}}=3.27 \times 10^{6}-1065.3 T \\
\sigma_{\mathrm{O}^{2-}}=3.34 \times 10^{4} \exp \left(-\frac{10300}{T}\right)
\end{array}
$$

These coupled equations were solved by the LBM. The details of the calculation methods are described in Refs. [23, 24]. In addition to the reference calculations, overpotential values were calculated by changing either of $i_{0}$ or $\sigma_{02}-$, whereas the other parameters were fixed at the values shown in Eqs. (14) and (16). The $i_{0}$ or $\sigma_{02}$-values were fitted so that the calculated overpotential can reproduce the experimental results. Assuming linear dependence of overpotential on current density at low current density, predicted polarization resistance were compared with the values obtained from impedance measurement at $\mathrm{OCV}$. Therefore, current density for the simulation was set at a small value of $0.01 \mathrm{~A} / \mathrm{cm}^{2}$.

\section{Results}

\section{Electrode performance}

Changes in terminal voltage between anode and reference electrode during the experiments are shown in Fig. 1. The result of the "10 redox test" is already described in Ref. [9]. During the " $220 \mathrm{~h}$ discharge test", voltage decreased gradually during discharge. On the other hand, during the " 10 redox test", voltage increased just after every redox treatment. After the subsequent discharge process, voltage decreased rapidly at the beginning, then kept on decreasing with a moderated rate. Repeating the redox-discharge 
cycles, voltage gradually decreased during the whole operation sequence. When we focus on the results of initial $20 \mathrm{~h}$ operations, "10 redox test" result shows lower voltage and faster degradation rate than the "220 h discharge test". Furthermore, "10 discharge test" shows some noisy voltage fluctuations. This can be ascribed to the individual difference between the cells and the experimental setup, e.g. contact between the current collecting mesh and the electrode, etc.

Changes in ohmic and polarization resistances obtained from the impedance measurement at OCV are shown in Fig. 2. During the "220 h discharge test", both ohmic and polarization resistances increased gradually. The ohmic resistances in the "10 redox test" also showed gradual increase, but little difference was found between the values before and after each redox treatment. Polarization resistance of the "10 redox test" shows decrease just after the redox and increase during subsequent discharge process. Repeating redox-discharge cycles, polarization resistance increased gradually during the entire experiment. 


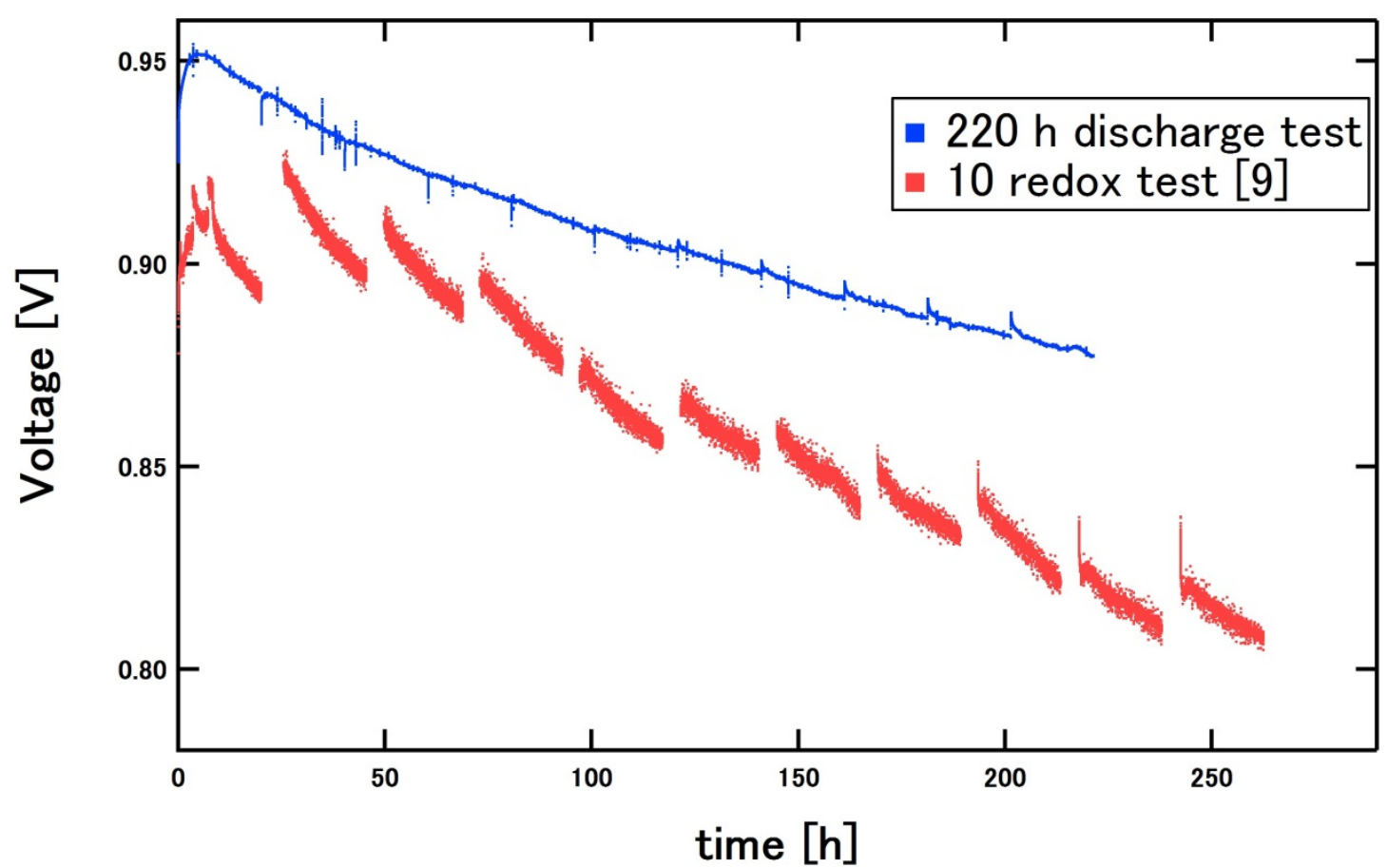

Figure 1: Changes in terminal voltage between anode and reference electrode. Results of "220 h discharge test" and "10 redox test" [9]

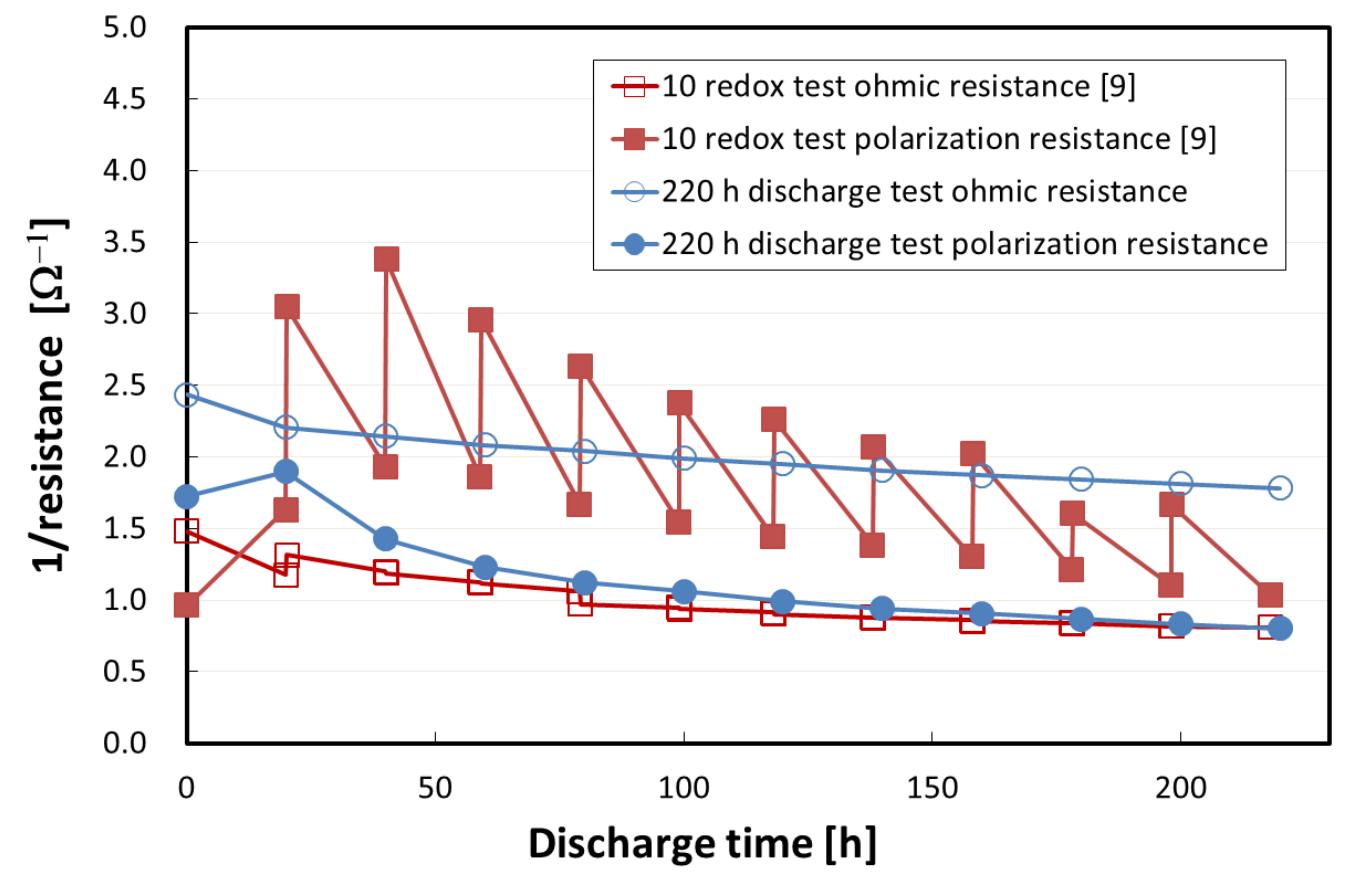

Figure 2: Changes in ohmic and polarization resistances. Results of "220 h discharge test" and "10 redox test" [9] 
Microstructure analysis

Cross-sectional images of the tested Ni-YSZ anodes are shown in Fig .3. It is seen that Ni particle becomes larger and round after the discharge process. On the other hand, Ni particle became elongated after the first redox treatment. During the following discharge process, Ni particle became round as can be seen in the " 1 redox and $20 \mathrm{~h}$ discharge" sample. Repeating redox-discharge cycles, Ni particle became elongated and fine as seen in the " 4 redox and $20 \mathrm{~h}$ discharge" and " 10 redox and $20 \mathrm{~h}$ discharge" samples.

Changes in the active TPB density during the " $220 \mathrm{~h}$ discharge test" and the " 10 redox test" are shown in Fig. 4. During the discharge operation, active TPB density decreased gradually. In the "10 redox test", active TPB density decreased during the first $20 \mathrm{~h}$ of discharge. Then, active TPB density increased after each redox treatment. During the following $20 \mathrm{~h}$ discharge, active TPB density decreased again. However, active TPB density gradually increased after repeating the redox-discharge cycles. 


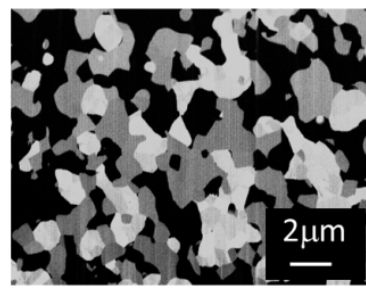

$\Rightarrow$ Discharge process

$\Rightarrow$ Redox

$\Rightarrow$ Cycle of redox-discharge process

Initial reduction
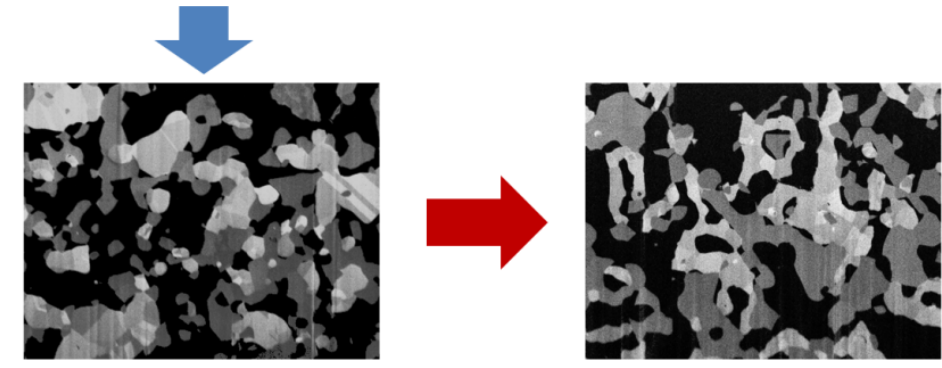

20h discharge

1 redox
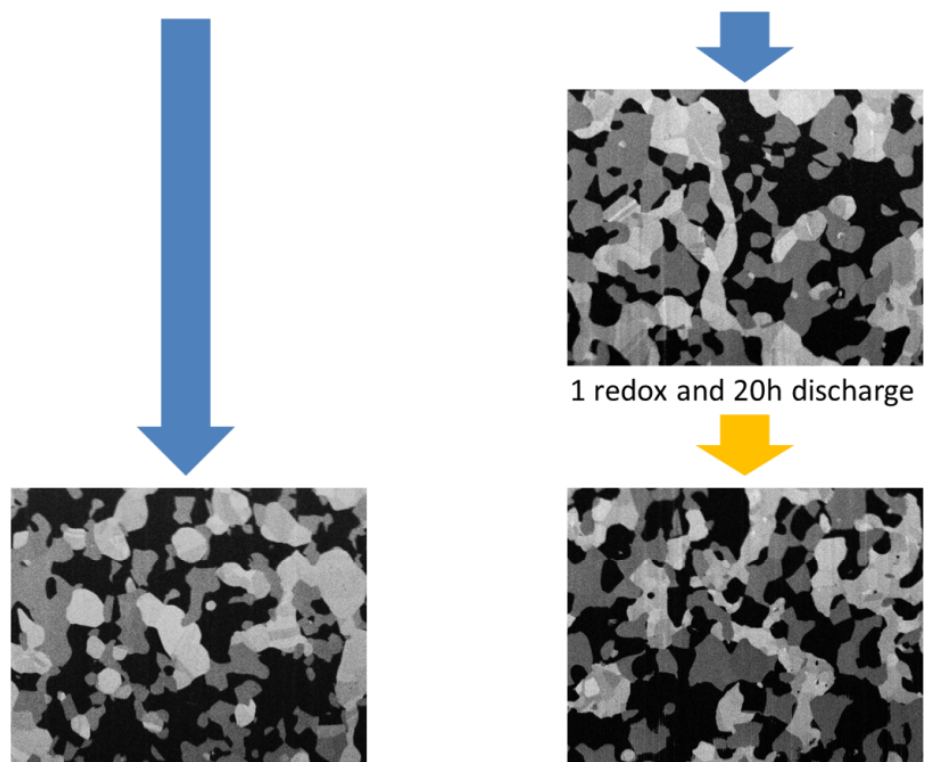

1 redox and $20 \mathrm{~h}$ discharge

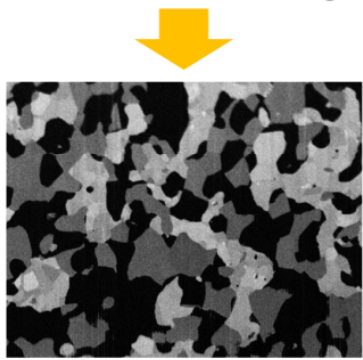

100h discharge

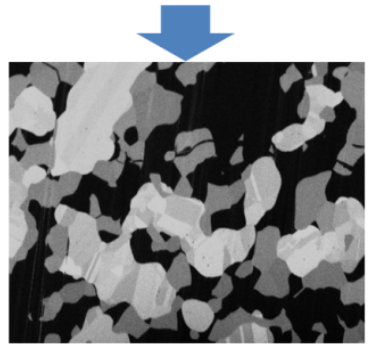

4 redox and $20 \mathrm{~h}$ discharge

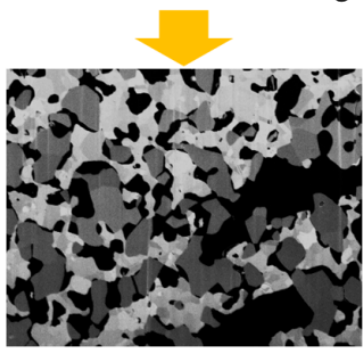

10 redox and $20 \mathrm{~h}$ discharge

Figure 3: SEM images of Ni-YSZ anodes for tested conditions. Bright, gray and dark phases correspond to $\mathrm{Ni}, \mathrm{YSZ}$ and pore, respectively. Images except for the " $220 \mathrm{~h}$ discharge test" are shown in Ref. [9] 


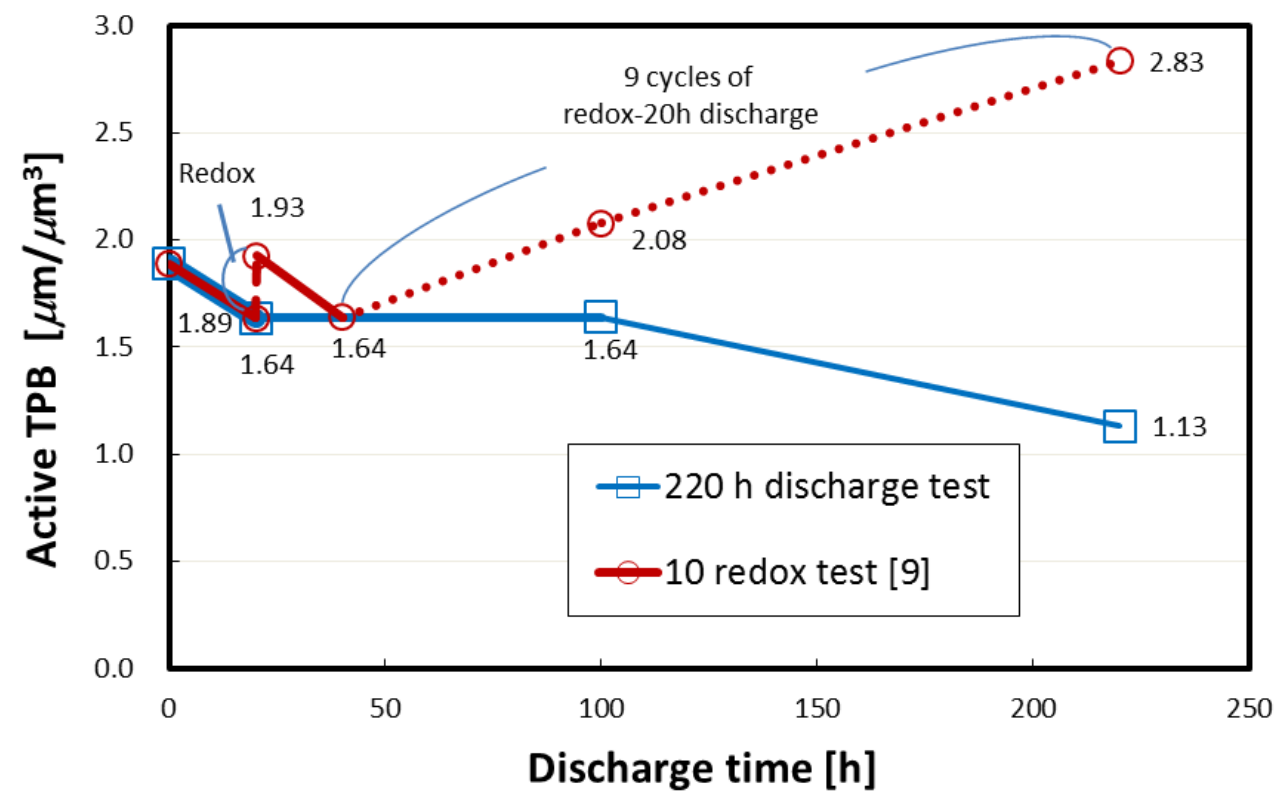

Figure 4: Changes in active TPB density. Results of " $220 \mathrm{~h}$ discharge" test and " 10 redox test" [9]

\section{Electrochemical simulation}

Overpotential values calculated by electrochemical calculation are summarized in Table 2. Large deviation is found between the experimental overpotential values and the calculated values when reference exchange current density and YSZ ionic conductivity values are used. For every samples, either the exchange current density or the YSZ ionic conductivity were fitted so that the predicted overpotential values match with the experimental ones.

The fitted exchange current densities and YSZ ionic conductivities are shown in Fig. 5. Both parameters showed similar trend during the tests. Their values decreased during the discharge processes except for the initial $20 \mathrm{~h}$ discharge process. After the first 
redox treatment, both parameters increased significantly. During the repeated redoxdischarge cycles, both parameters decreased.

Table 2 Results of electrochemical simulations

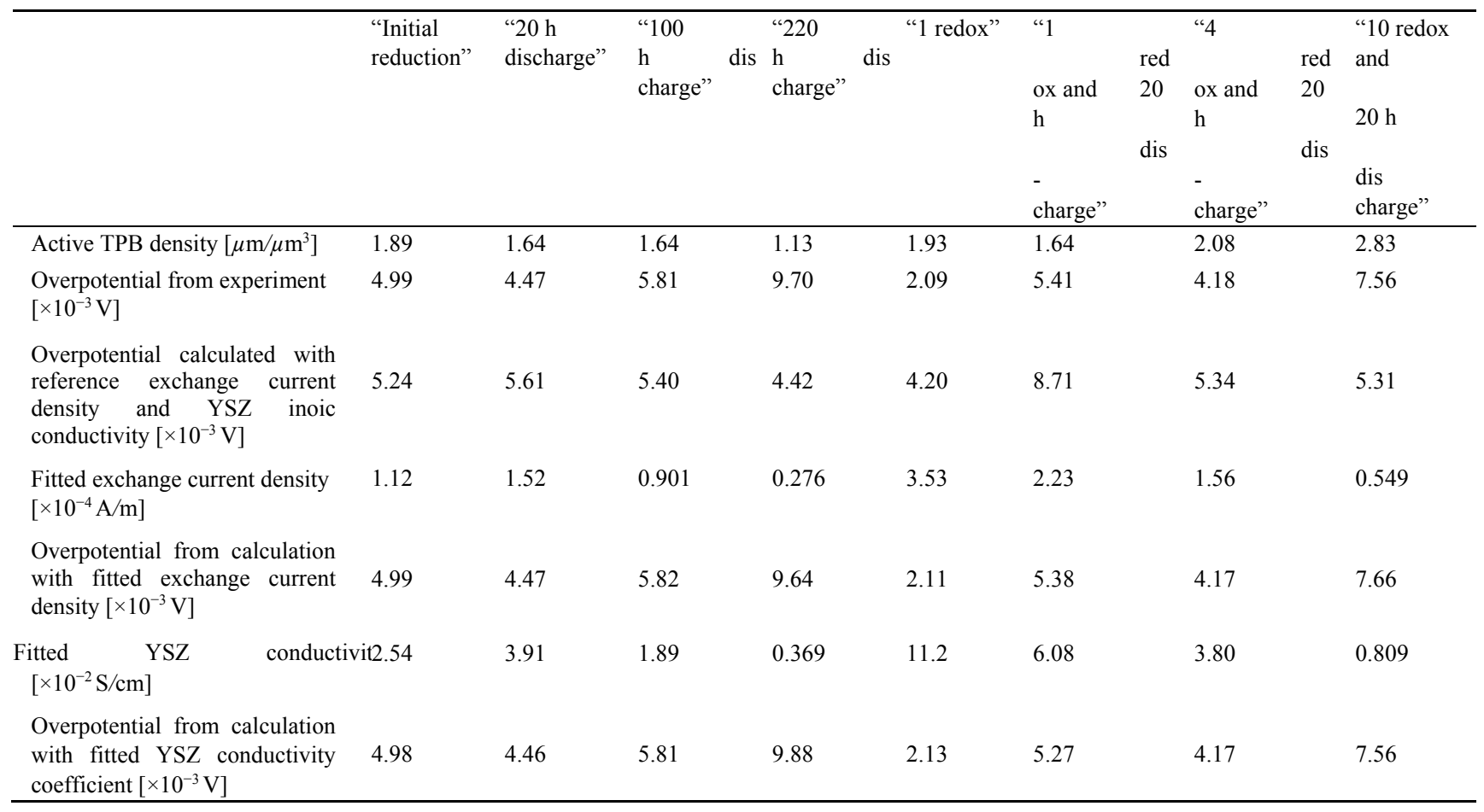
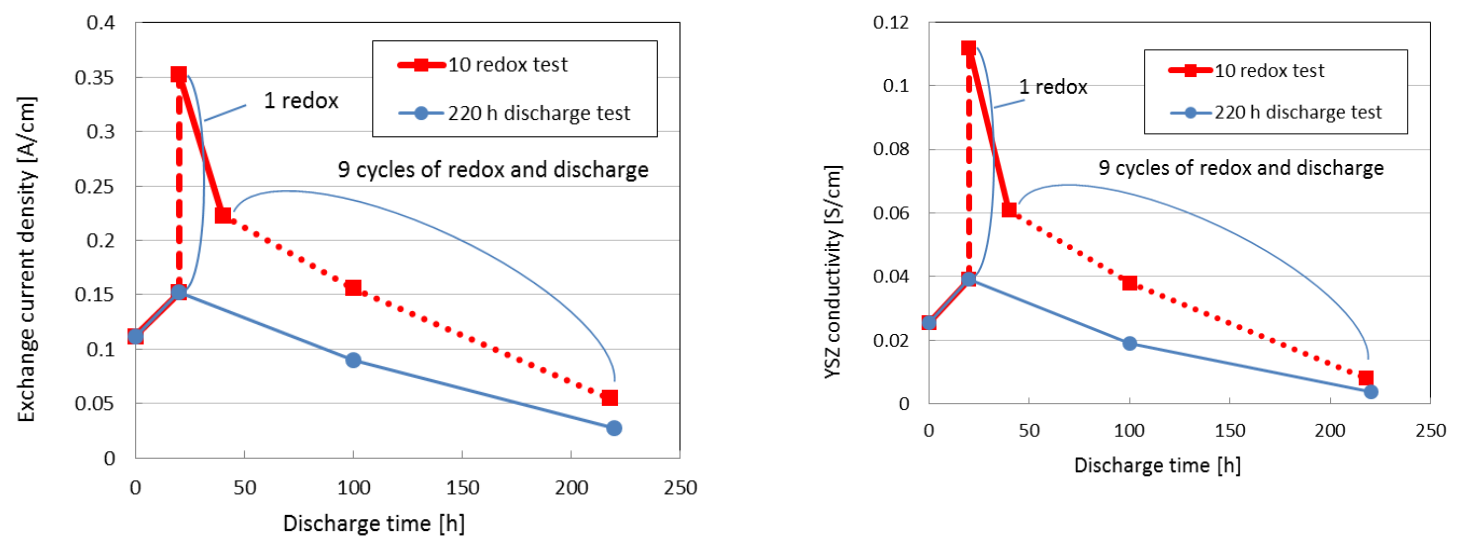

Figure 5: Fitted parameters. (a) Exchange current density, and (b) YSZ ionic conductivity. 


\section{Discussion}

As shown in Figs. 1 and 2, the electrode performance changed differently in the discharge operation and the redox cycles operation. Constant increase of polarization resistance found in the " $220 \mathrm{~h}$ discharge test" is consistent with the performance change of "100 h discharge test" reported in Ref. [9]. In the "10 redox cycles test", polarization resistance increased during the discharge process, whereas the polarization resistance decreased just after the redox treatment. However, as the redox-discharge cycles are repeated, polarization resistance gradually increased. Thus, anode performance degraded both in the "220 h discharge test" and in the "10 redox test", regardless of the redox treatment.

Gradual decrease in active TPB density was observed in "220 h discharge test" as shown in Fig. 4. This is qualitatively consistent with the increase of polarization resistance shown in Fig. 2. The active TPB density increased after the first redox as shown in Fig. 4, which is also consistent with the decrease of polarization resistance shown in Fig. 2. However, increase in active TPB density observed after repeating redoxdischarge cycles is inconsistent with the overall increase of polarization resistance during the "10 redox test". The increase of active TPB density is closely related with the deformation of Ni particles into small and elongated shapes, as described in Ref. [9].

The fitted exchange current density and YSZ ionic conductivity are shown in Fig. 5. Changes of the fitted exchange current density and YSZ ionic conductivity values in "10 redox test" and "220 h discharge test" showed similar tendency as the inverse of polarization resistance shown in Fig. 2. In contrast to the increase of active TPB density after repeated redox-discharge cycles, the exchange current density or YSZ ionic conductivity must reduce in order to reproduce the experimental trend. The increase of exchange current density and YSZ ionic conductivity just after redox treatment, and the 
decrease of those parameters during discharge indicate that it is insufficient to reproduce quantitatively the experimental results only by the microstructure changes. In addition, gradual decrease of exchange current density or YSZ ionic conductivity are found regardless of the redox cycles, which indicates that it is not appropriate to use fixed values for these parameters even in normal operations.

Correlations for chemical reaction rate at TPB and impurity segregation is proposed by Utz, et al. [15]. It is reported that the marks formed by impurity segregation adjacent to the TPB lines migrates accompanied by the recession of TPB lines due to the sintering of Ni. In the present study, drastic change of TPB position is expected due to the volume expansion during oxidation and shrinkage during reduction. Furthermore, because of the supply of oxygen during oxidation process, removal of the impurities which react with oxygen might takes place. Therefore, appearance of the clean TPB without impurities after redox treatment may explain the higher local exchange current density values.

Hattori, et al. [17] studied the change in ionic conductivity of YSZ. They found that the conductivity decreased by about $20 \%$ after $1000 \mathrm{~h}$ in air. In the present study, the decreases in the YSZ conductivity, i.e. $85 \%$ after the " $220 \mathrm{~h}$ discharge test" and $68 \%$ after the "10 redox test", were much faster than the reported values. However, it is reported that the decrease in ionic conductivity is accelerated with the presence of $\mathrm{Ni}$ phase. Coors, et al. [19] reported ionic conductivity degradation of YSZ doped with $\mathrm{NiO}$ which simulates the co-sintered state of YSZ and $\mathrm{NiO}$. Decrease in conductivity was almost $50 \%$ within $100 \mathrm{~h}$ at $1000{ }^{\circ} \mathrm{C}$. It is reported that $\mathrm{Ni}$ reduction at grain boundaries enhances transition from cubic to tetragonal phases and results in the conductivity decrease. Shimonosono, et al. [16] also studied the degradation of conductivity and phase translation of NiO-doped YSZ. Ionic conductivity decreased about $44 \%$ after $170 \mathrm{~h}$ at 
$900{ }^{\circ} \mathrm{C}$. Butz, et al. [20] also reported that the degradation starts under the reduction condition and the conductivity decreased about $30 \%$ during $100 \mathrm{~h}$. The decrease in the fitted conductivity in the present study is larger than those results. However, YSZ phase transition can be considered as one of the causes for the decrease of YSZ conductivity during discharge process. The trends of exchange current density and ionic conductivity variations are similar as shown in Fig. 5. However, the changes of exchange current density and ionic conductivity of YSZ affect electrochemical potential distribution in a totally different way. Electrochemical potential distributions of the oxide ion for "10 redox and $20 \mathrm{~h}$ discharge" are shown in Fig. 6. Comparing Fig. 6 (a) and (b), it is clearly seen that the distribution of oxide ion extends toward the current collector side when the exchange current density is fitted. This is because that more reaction site is required to maintain the same polarization level with inactivated electrochemical reaction rate. On the other hand, as shown in Fig. 6 (c), distribution of oxygen ion potential is suppressed closer to the electrolyte/anode interface when YSZ ionic conductivity is fitted. This is because the diffusion of oxygen ion is inhibited due to the lower conductivity. In Fig. 7, distributions of electronic and ionic currents in the "10 redox and $20 \mathrm{~h}$ discharge" sample are shown. Each line corresponds to the state which is shown in Fig. 6 (a), (b) or (c). Reaction areas are extended or suppressed depending on the fitted parameters, which are consistent with the results shown in Fig. 6. Here, the effective thickness $t_{\text {eff }}$ is defined as the electrode thickness where the $90 \%$ of the ionic current is transferred into electronic

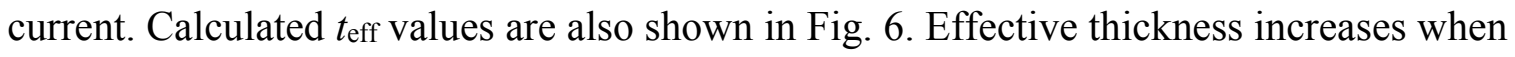
the exchange current density is fitted, whereas it decreases when the YSZ ionic conductivity is fitted. The contribution ratio of material transport and electrochemical reaction also can be estimated by the Thiele modulus $\Gamma$ [29]. Thiele modulus $\Gamma$ is defined as follows: 


$$
\Gamma^{2}=\frac{i_{0} \overline{L_{\mathrm{TPB}}} F\left(\theta_{a}+\theta_{c}\right)\left(\rho_{\mathrm{ion}}^{\mathrm{eff}}+\rho_{\mathrm{elec}}^{\mathrm{eff}}\right)}{R T} t_{\mathrm{e}}^{2}
$$

Here, $\overline{L_{\mathrm{TPB}}}$ represents the averaged active TPB density inside the whole electrode, and $t_{\mathrm{e}}$ represents the electrode thickness. $\rho_{\text {ion }}^{\text {eff }}$ and $\rho_{\text {elec }}^{\text {eff }}$ represent the effective resistances of ionic and electronic conductions, respectively. $R$ is the gas constant and $T$ is the working temperature. Since the electronic conductivity of $\mathrm{Ni}$ is much larger than the ionic conductivity of YSZ, $\rho_{\text {elec }}^{\text {eff }}$ can be neglected. Effective conductivity $\sigma_{\text {eff }}$ is defined using the tortuosity factor $(\tau)$ and the volume fraction $(\varepsilon)$ as follows:

$$
\sigma_{\mathrm{O}^{2-}}^{\mathrm{eff}}=\frac{\epsilon}{\tau} \sigma_{\mathrm{O}^{2-}}
$$

where values of $\tau=9.45$ and $\varepsilon=0.303$ are chosen from our previous work [9]. Finally, Eq. (17) can be rewritten as follows:

$$
\Gamma^{2}=\frac{i_{0} \overline{L_{\mathrm{TPB}}} F\left(\theta_{a}+\theta_{c}\right) \tau}{\epsilon \sigma_{\mathrm{O}^{2}}-R T} t_{\mathrm{e}}^{2}
$$

Calculated $\Gamma$ values are listed in Fig. 6. We can see that the $\Gamma$ decreases when the exchange current density is fitted, and $\Gamma$ increases when the YSZ ionic conductivity is fitted. Increase of $\Gamma$ corresponds to the increase of ionic conduction resistance inside the electrode. When $\Gamma$ is larger than 3, effective thickness is proportional to the inverse of $\Gamma$ [29]. In Fig. 8, normalized effective thickness and inverse of Thiele modulus are shown for comparison. As can be seen from the figure, both values show similar trends. As these parameters indicate, we can clearly see that effective thickness extends when the TPB reaction is inhibited, whereas effective thickness becomes shorter when ionic conductivity is suppressed.

Thus, polarization characteristics inside the electrode is totally different depending on the dominant changes of the parameters. In this study, fitting of exchange current density or YSZ ionic conductivity were conducted by fixing the other at a standard value. 
Therefore, contributions from the two mechanisms cannot be simultaneously evaluated. It is difficult to estimate the quantitative contributions either from the exchange current density or from the YSZ ionic conductivity. To reduce the degradation which originates from the change in YSZ ionic conductivity, use of alternative material can be one of the solutions. It is reported that $10 \mathrm{YSZ}$ or $9.5 \mathrm{YSZ}$ shows slower transition from cubic to tetragonal phases, and thus shows slower degradation rates than 8YSZ [17-18].

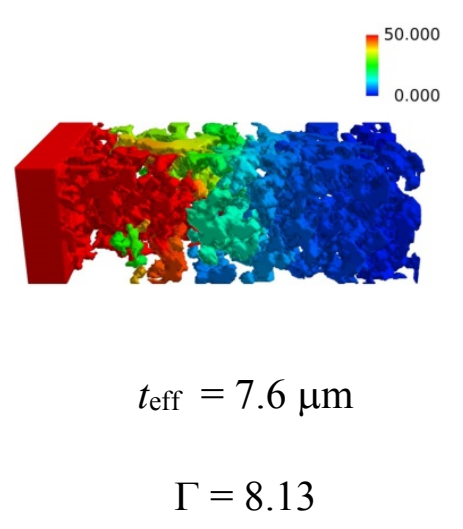

(a)

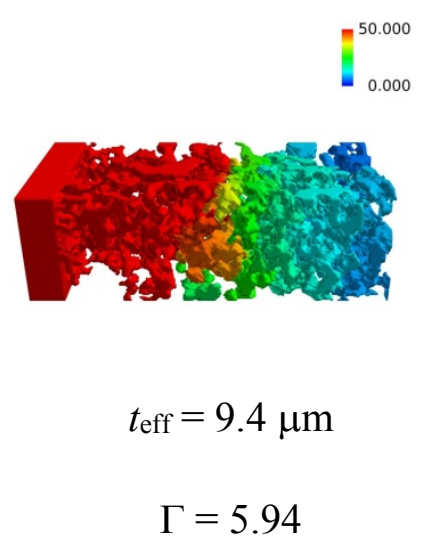

(b)

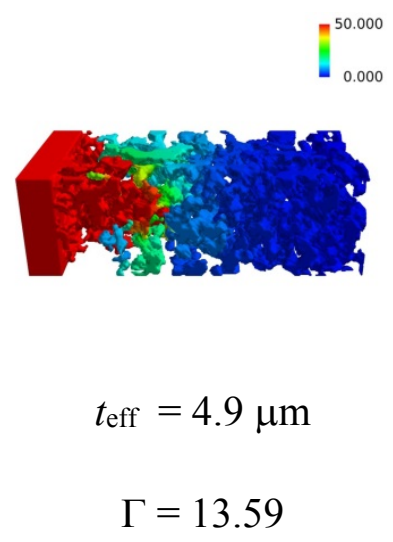

(c)

Figure 6 : Electrochemical potential distribution of oxide ion $[\mathrm{J} / \mathrm{mol}]$ in $\mathrm{YSZ}$ microstructure of "10 redox and $20 \mathrm{~h}$ discharge" sample. Left side is the electrolyte and right side corresponds to the current collector. (a) With standard values of exchange current density and YSZ ionic conductivity, (b) with fitted exchange current density values, and (c) with fitted value of ionic conductivity of YSZ. The values shown below are effective thickness $t_{\mathrm{eff}}$ and Thiele modulus $\Gamma$. 


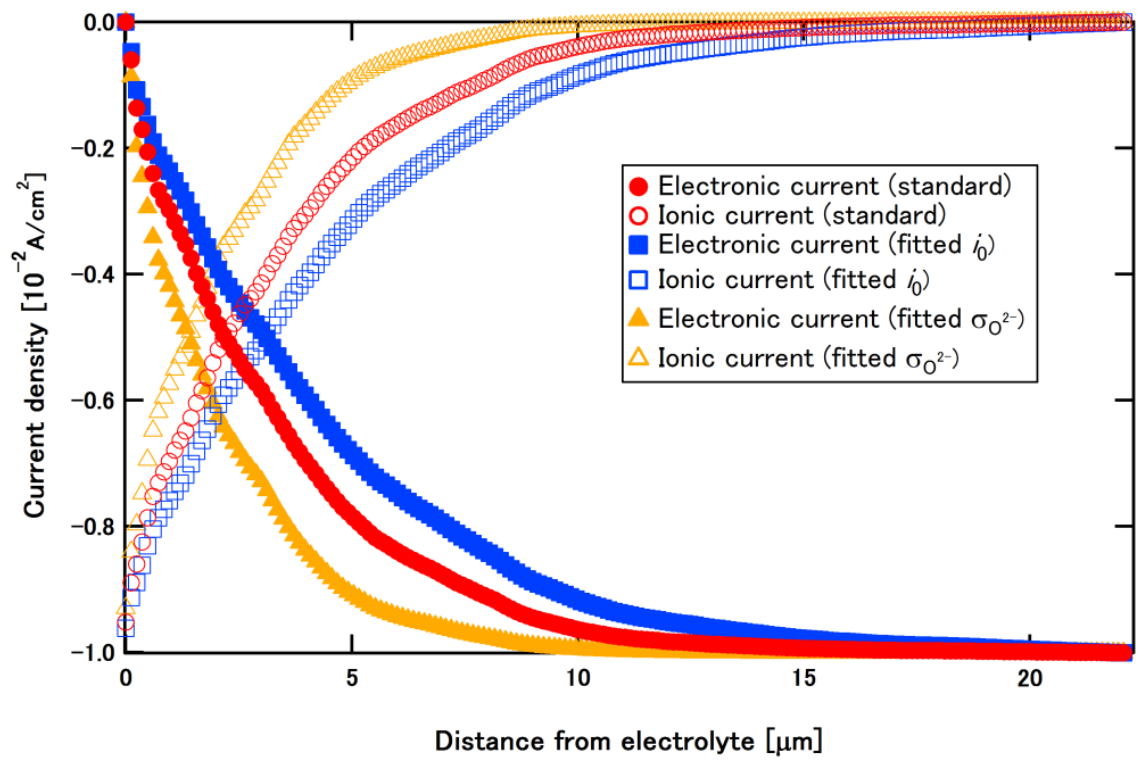

Figure 7 : Distributions of electronic and ionic currents in the "10 redox and $20 \mathrm{~h}$ discharge" sample. Left side is the electrolyte and right side corresponds to the current collector. Red symbols represent electronic and ionic current densities with standard values of exchange current density and YSZ ionic conductivity. Blue symbols are for fitted exchange current density values (fitted $i$ ), and the yellow are the results for fitted YSZ ionic conductivity (fitted $\sigma 02-$ ). 


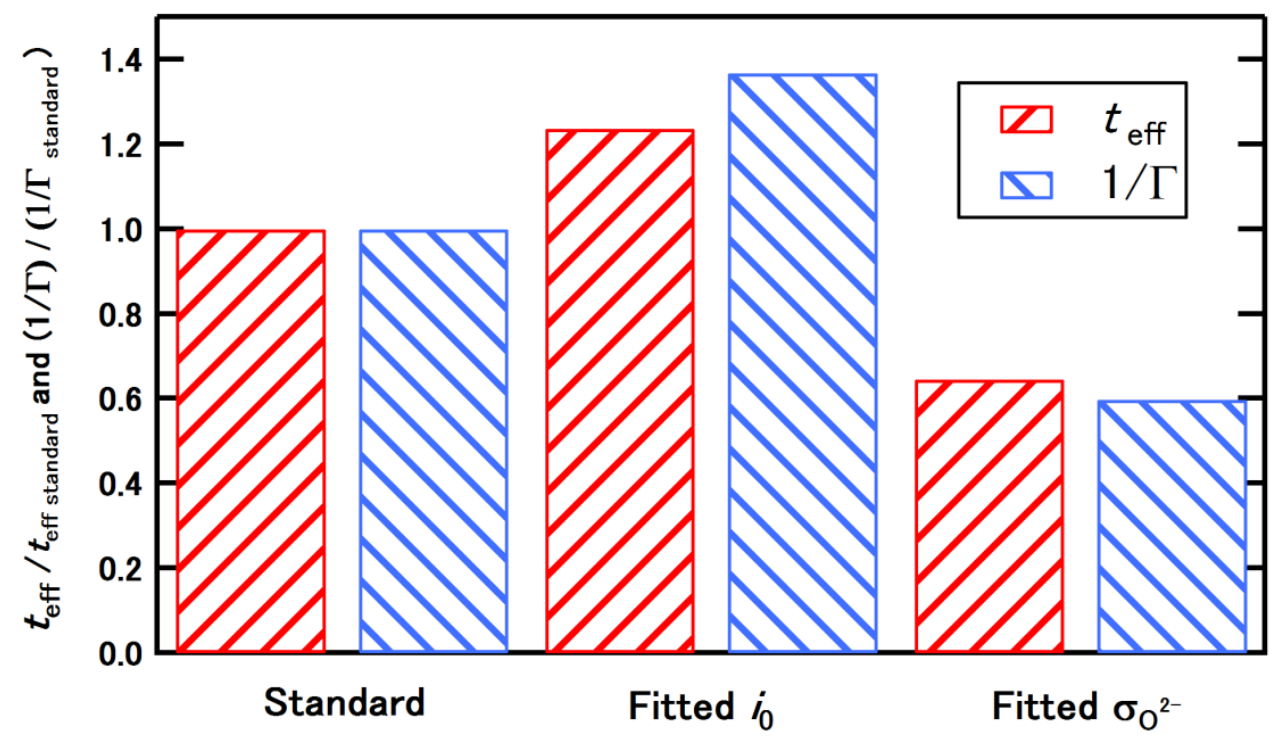

Figure 8 : Comparison of effective thickness and inverse of Thiele modulus normalized by the values at the standard case.

\section{Conclusion}

Performance changes of Ni-YSZ anode during discharge operation and redox cycle operation were investigated. Polarization resistance increased during the discharge process and decreased after each redox treatment. After repeating the redox-discharge cycles, polarization resistance gradually increased. From the 3D microstructure reconstruction by FIB-SEM, active TPB density increased after the redox treatment and decreased after the discharge processes, which is consistent with the change in polarization resistance. After repeating the redox-discharge cycles, active TPB density increased, which is inconsistent with the gradual increase in polarization resistance. Values of exchange current density or YSZ ionic conductivity were fitted by the electrochemical simulations using the reconstructed microstructures. Fitted values showed increase after each redox treatment and decrease after discharge processes or 
redox-discharge cycles. These changes showed same tendency as the experimental results. Therefore, it is considered that, in addition to the microstructure change, the influence of the changes in these parameters should be taken into account to predict the performance change.

\section{Acknowledgements}

This work was partly supported by New Energy and Industrial Technology Development Organization (NEDO) and Japan Science and Technology Agency (JST).

\section{References}

[1] D. Sarantaridis, A. Atkinson, Fuel Cells 07 (3) (2007) 246-258.

[2] A. Faes, A. Nakajo, A. Hessler-Wyser, D. Dubois, A. Brisse, S. Modena, J.V. Herle, J. Power Sources 193 (2009) 55-64.

[3] M. Ettler, H. Timmermann, J. Malzbender, A. Weber, N.H. Menzler, J. Power Sources 195 (2010) 5452.

[4] J. Laurencin, G. Delette, O. Sicardy, S. Rosini, F. Lefebvre-Joud, J. Power Sources 195 (2010) 2747-2753.

[5] D. Waldbillig, A. Wood, D.G. Ivey, J. Power Sources 145 (2005) 206-215.

[6] J. R. Wilson, W. Kobsiriphat, R. Mendoza, H.-Y. Chen, J. M. Hiller, D. J. Miller, K. Thornton, P. W. Voorhees, S. B.

Adler, S. A. Barnett, Nature Materials 5 (2006), 541-544.

[7] H. Iwai, N. Shikazono, T. Matsui, H. Teshima, M. Kishimotoa, R. Kishida, D. Hayashi, K. Matsuzaki, D. Kanno, M. Saito, H. Muroyama, K. Eguchi, N. Kasagi, H. Yoshida, J. Power Sources 195 (2010) 955-961.

[8] N. Viveta, S. Chupina, E. Estradea, A. Richardb, S. Bonnamyc, D. Rochaisa, E. Brunetona, J. Power Sources 196 (2011)

9989-9997.

[9] T. Shimura, Z. Jiao, S. Hara, N. Shikazono, J. Power Sources 267 (2014) 58-68.

[10] B. de Boer, Ph.D. Thesis, University of Twente (1998).

[11] A. Bieberle, L.P. Meier, L.J. Gauckler, J. Electrochem. Soc. 148 (6) (2001) A646A656. 
[12] A. Utz, H. Stormer, A. Leonide, A. Weber, E. Ivers-Tiffee, J. Electrochem. Soc. 157 (6) (2010) B920-B930.

[13] M. Mogensen, K. V. Jensen, M. J. Jorgensen, S. Primdahl, , Solid State Ionics 150 (2002) 123-129.

[14] K. V. Hansen, K. Norrman, M. Mogensen, J. Electrochem. Soc., 151(9) (2004) A1436-A1444.

[15] A. Utz, K.V. Hansen, K. Norrman, E. Ivers-Tiffee, M. Mogensen, , Solid State Ionics 183 (2011) 60-70.

[16] T. Shimonosono, H. Kishimoto ., M. E. Brito, K. Yamaji, T. Horita, H. Yokokawa, Solid State Ionics 225 (2012) 69-72.

[17] M. Hattori, Y. Takeda, J.-H. Lee, S. Ohara, K. Mukaic, T. Fukui, S. Takahashi, Y. Sakaki, A. Nakanishi, J. Power Sources 131 (2004) 247-250.

[18] M. Hattori, Y. Takeda, S Ohara, J.-H. Lee, K. Mukai, T. Fukui, Y. Sakaki, A. Nakanishi, J. Jpn. Soc. Powder Powder Metallurgy 50 (4) (2003) 297-301.

[19] W.G. Coors, J.R. O 'Brien, J.T. White, Solid State Ionics 180 (2009) 246-251.

[20] B. Butz, A. Lefarth, H. Stormer, A. Utz, E. Ivers-Tiffee, D. Gerthsen, Solid State Ionics 214 (2012) 37-44.

[21] Y. Chen, S. Chen, G. Hackett, H. Finklea, X. Song, K. Gerdes, Solid State Ionics 204-205 (2011) 87-90.

[22] S. Chen, Y. Chen, H. Finklea, X. Song, G. Hackett, K. Gerdes, Solid State Ionics 206 (2012) 104-111.

[23] N. Shikazono, D. Kanno, K. Matsuzaki, H. Teshima, S. Sumino, N. Kasagi, J. Electrochem. Soc. 157 (5) (2010) B665-

B672.

[24] D. Kanno, N. Shikazono, N. Takagi, K. Matsuzaki, N. Kasagi, Electrochimica Acta 56 (2011) 4015-4021.

[25] T. Kawada, N. Sakai, H. Yokokawa, M. Dokiya, J. Electrochem. Soc. 137 (1990) 3042-3047.

[26] J.B. Young, B. Todd, Int. J. Heat. Mass. Transfer 48 (2005) 5338-5353.

[27] U. Anselmi-Tamburinia, G. Chiodelli, M. Arimondi, F. Maglia, G. Spinolo, Z.A.Munir, Solid State Ionics 110 (1998)

$35-43$.

[28] J.R. Ferguson, J.M. Fiard, R. Herbin, J. Power Sources 58 (1996) 109-122.

[29] P. Costamagna, P. Costa., V. Antonucci, Electrochimica Acta 43 (3-4) (1998), 375-394. 